\title{
Multilevel Surgery in Moderate to Severe Obstructive Sleep Apnea Patients
}

\author{
1Jumroon Tungkeeratichai, ${ }^{2}$ Navarat Apirakkittikul, ${ }^{3}$ Somyos Kunachak
}

\begin{abstract}
Objective: The aim of this study was to investigate the objective and subjective effectiveness of multilevel surgery, i.e. combined lingualplasty with new technique of partial posterior glossectomy (PPG) and uvulopalatopharyngoplasty in moderate to severe obstructive sleep apnea (OSA) patients.
\end{abstract}

Study design and setting: Retrospective study of 60 OSA patients undergoing multilevel surgery for the treatment of moderate to severe OSA.

Results: Preoperative mean apnea hypopnea index (AHI) was 57.5 events/h and preoperative mean lowest $\mathrm{SpO}_{2}$ was $79.1 \%$. After multilevel surgery, postoperative mean AHI significantly decreased to 29.7 events/h $(p<0.001)$ and postoperative mean lowest $\mathrm{SpO}_{2}$ increased to $84.4 \%(\mathrm{p}<0.001)$. Patients had postoperative follow-up assessments for 1 to 3 years. Results of surgery was classified as curative in $35 / 60(58.3 \%)$ of patients, and as effective, i.e. postoperative $\mathrm{AHI}$ less than preoperative $\mathrm{AHI}$ in $52 / 60$ patients $(86.7 \%)$. Surgery was ineffective in $8 / 60$ (13.3\%) patients. Early postoperative complications comprised early velopharyngeal insufficiency (VPI) $20 \%$ (12/60), dysarthria $20 \%(12 / 60)$ and wound dehiscence $3.33 \%(2 / 60)$ but without serious complications after 1 year.

Conclusion: Combined lingualplasty (with new PPG) and uvulopalatopharyngoplasty (UPPP) as multilevel surgery can be an effective treatment of choice for patients with moderate to severe OSA. No medium-term serious complication was found.

Keywords: Apnea hypopnea index, Glossectomy, Lateral pharyngoplasty, Multilevel surgery in obstructive sleep apnea, Obstructive sleep apnea, Uvulopalatoplasty.

How to cite this article: Tungkeeratichai J, Apirakkittikul N, Kunachak S. Multilevel Surgery in Moderate to Severe Obstructive Sleep Apnea Patients. Int J Otorhinolaryngol Clin 2014;6(3):87-91.

Source of support: Nil

Conflict of interest: None

\section{INTRODUCTION}

Obstructive sleep apnea (OSA) is a relatively common and potentially fatal disorder affecting 2 to $4 \%$ of

${ }^{1}$ Assistant Professor, ${ }^{2}$ Lecturer, ${ }^{3}$ Professor

${ }^{1-3}$ Department of Otolaryngology, Faculty of Medicine, Ramathibodi Hospital, Mahidol University, Bangkok, Thailand

Corresponding Author: Jumroon Tungkeeratichai, Assistant Professor, Department of Otolaryngology, Faculty of Medicine Ramathibodi Hospital, Mahidol University, Bangkok 10400 Thailand, Phone: 0-2201-1515, e-mail: jumroont@yahoo.com middle-aged adults. ${ }^{1}$ Generally, patients have narrow and collapsible airways. ${ }^{2,3}$ The Sleep Heart Health Study and the Wisconsin Sleep Cohort ${ }^{4,5}$ have demonstrated that the consequences of the collapse of the upper airway are hypertension, cardiovascular disease and cerebral vascular accident due to sleep fragmentation, nocturnal hypoxemia and increased sympathetic tone. ${ }^{6,7}$ Nasal continuous positive airway pressure (CPAP) is considered as the gold standard and the primary treatment for OSA but is limited by poor long-term compliance. ${ }^{8,9}$ Upper airway surgery is an important treatment option for patients with OSA, particularly for those who have failed CPAP therapy.

Main aim of surgery was to reduce anatomical upper airway obstruction. Since the report by Fujita et $\mathrm{al}^{10}$ in 1981, uvulopalatopharyngoplasty (UPPP), with the aim of enlarging the potential airspace in the oropharynx, has become a common surgical procedure for the OSA.

Reported success rates of UPPP for OSA range between 16 and $83 \%$, depending on the definition of a positive outcome and selection of patients; according to international journals, criteria for surgical success or cure of OSA after UPPP are: (i) a postoperative $50 \%$ reduction in apnea hypopnea index (AHI) and (ii) a residual (postoperative) AHI $\leq 20$ events/hour. ${ }^{11-16}$

However, one should consider multiple sites of obstruction in severe cases OSA. Furthermore, Riley et $\mathrm{al}^{17-19}$ were the first to advocate the simultaneous performance of a multilevel surgery for these patients and their invasive technique included maxillary and mandibular advancement. Despite as high a success rate of $95 \%$ being reported, ${ }^{18,20}$ more publications are needed since many Asian patients may not accept such an extensive surgery. Nevertheless, in selected patients extensive surgery may have a role in treatment of OSA. ${ }^{21}$

Regarding lingual operations, although some authors have described midline glossectomy (and/or lingualplasty) for 'failed UPPP' patients, there has been no previous report on partial posterior glossectomy (PPG) with suturing as part of lingualplasty like ours.

The aim of study was to investigate the objective and subjective effectiveness of the multilevel surgery: partial midline glossectomy (PMG) and PPG as party of lingualplasty together with UPPP as combined multilevel surgery in moderate to severe OSA patients with multilevel airway obstructions. 


\section{MATERIALS AND METHODS}

A retrospective analysis was conducted on 60 consecutive patients who underwent multilevel surgery, i.e. combined lingualplasty (with new PPG) and UPPP for moderate to severe OSA, from January 2004 to 2012. All these patients had attended the snoring clinic in Ramathibodi Hospital (a tertiary center receiving patients from all parts of Thailand).

Inclusion criteria were: patients aged 20 to 70 years, significant symptoms of habitual snoring and/or excessive daytime somnolence, no previous upper airway surgical treatment for OSA, failure or refusal of conservative treatments, e.g. oral appliances or CPAP, retropalatal and retrolingual obstructions as identified by the Müller maneuver, absence of significant maxillofacial abnormalities and $\mathrm{AHI} \geq 15$ events/hour.

Exclusion criteria were: pregnancy, significant heart disease (Canadian class 3-4), coagulopathy, psychiatric disease, significant maxillofacial abnormalities, e.g. sellanasion-B (SNB) angle $<76^{\circ}$ and sella-nasion-A (SNA) angle $<78^{\circ}$, and/or history of previous upper airway surgical treatment for OSA.

Comprehensive preoperative assessments were carried out and included thorough history and physical examination. Patients also completed the Epworth's sleepiness scale (ESS) snore scale (SS) and some questionnaires. Height, weight, neck circumference, BMI (body mass index-calculated as weight in kilograms divided by height in meters squared), and vital signs were also documented. Examination included the documentation of soft palatal redundancy, uvula size and thickness, Mallampati grades, and adenoid and tonsillar sizes. Nasal cavity and laryngeal examination with a flexible fiberoptic endoscopy was also performed; and, Müller maneuver was performed on each patient. Investigations included radiographic cephalometry, thyroid function test, electrocardiogram (EKG) and polysomnography (PSG). All patients underwent lingualplasty (including new PPG). Three months after multilevel surgery, PSG tests were repeated to compare preoperative and postoperative values. Surgical success in this study was defined as postoperative AHI reduction of at least 50\% or postoperative (residual) AHI $<20$ events/hour.

\section{OPERATIVE PROCEDURES}

Initially, tonsillectomy was performed by incision of soft palate $-1 \mathrm{~cm}$ lateral to uvula by an angle $45^{\circ}$ to the vertical. Then, suturing anterior pharyngeal pillar to posterior pharyngeal pillar was made by three 'vicryl 3-0' stitches (Figs 1A and B). Uvulopalatal flap was done by retraction of the uvula superiorly toward the hardsoft palate junction after limited removal of the uvula (leaving $1 \mathrm{~cm}$ of uvula remnant) and was completed by lateral pharyngoplasty (LP). Such modified UPPP and LP (Figs 1A and B) will be regarded as 'UPPP' in this study.

Lingualplasty was performed by the following procedures: (i) PMG (resecting spindle-shaped tongue lateral from midline 0.5 to $1 \mathrm{~cm}, 4.5 \mathrm{~cm}$ long, $1 \mathrm{~cm}$ thick posterior abut circumvalate papillae), (ii) PPG (resecting spindle-shaped base of tongue lateral from midline 1.5 $\mathrm{cm}, 1$ to $1.5 \mathrm{~cm}$ posterior, $1 \mathrm{~cm}$ thick (Figs 2 and 3), and (iii) suturing (using J-shaped needle with 'vicryl 2-0' to suture the midline for 3 stitches and to suture base of tongue 3 stitches) for lingualplasty (Fig. 4). Overall surgery took approximately 60 to 90 minutes and all surgical procedures were performed by two experienced surgeons.

All patients remained on endotracheal tube for 3 days and were hospitalized for at least 4 nights (risk management for possible tongue edema). In addition, an antibiotic was given for 3 days (amoxyclavulonic acid 1.2 gm intravenous every 8 hours) and normal saline was used to irrigate oral cavities.

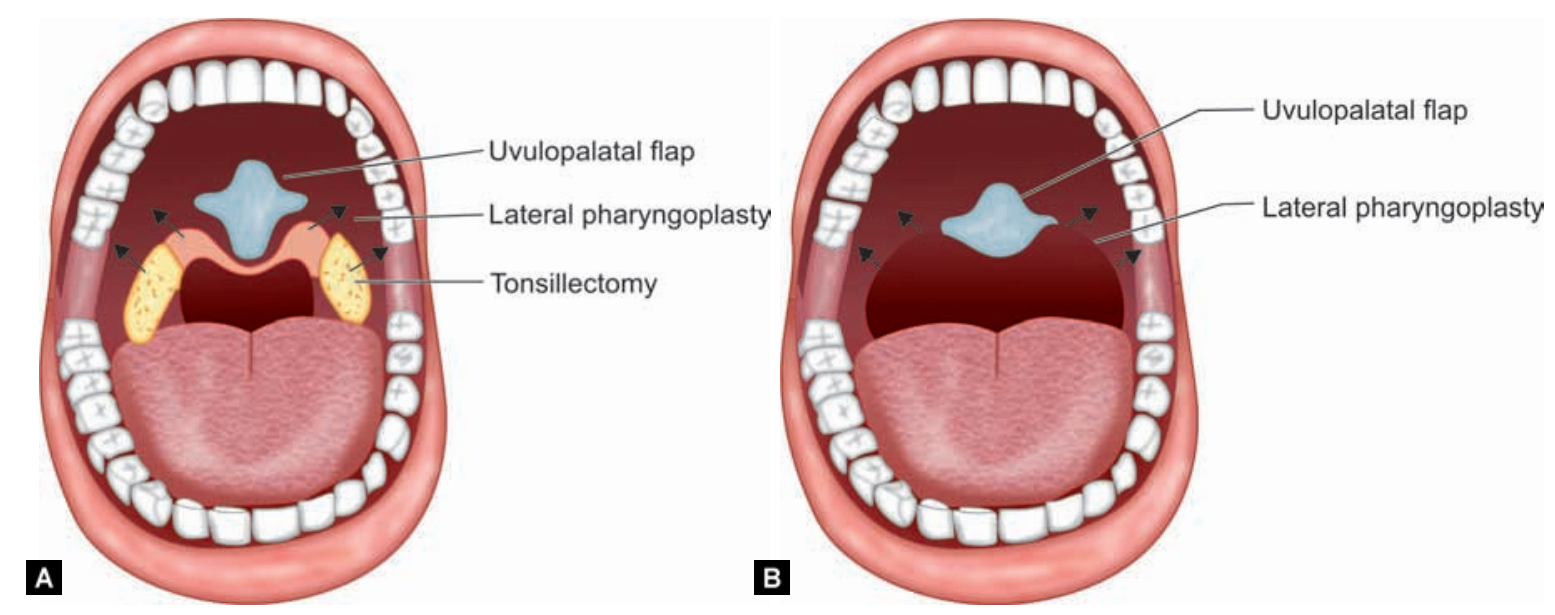

Figs 1A and B: The modified uvulopalatopharyngoplasty (tonsillectomy, lateral pharyngoplasty and uvuloplatal flap) 


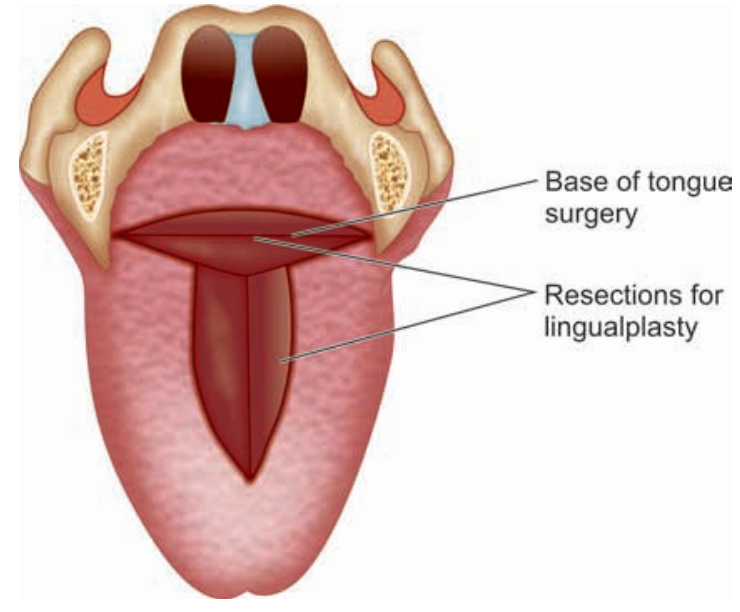

Fig. 2: Technique for lingualplasty

\section{STATISTICAL ANALYSIS}

Subject demographic and treatment outcomes were summarized as mean SD for continuous variables. The distributions of mean lowest $\mathrm{SpO}_{2}$ between time points and $\mathrm{AHI}$ were compared using the paired t-test. A paired t-test was also done to assess statistically significant differences between preoperative and postoperative parameters. Results were accepted to be significant for a $p$-value of $<0.05$. Statistical analyses were performed using statistical software (SPSS 11.9).

\section{RESULTS}

In this study, there were 60 multilevel surgical patients whose characteristics and parameters are shown (Table 1).

Mean preoperative AHI decreased significantly from 57.5 events/hour (SD 24.38 events/hour) to mean postoperative AHI of 29.7 events/hour (SD 25.44 events/ hour) ( $\mathrm{p}<0.001$ ); and, the mean preoperative lowest $\mathrm{SpO}_{2}$ increased significantly from $79.1 \%$ (SD $11.07 \%$ ) to $84.4 \%$ (SD 7.84\%) $(\mathrm{p}<0.001)$ (Table 2).

If 'curative' surgical success for OSA is considered (criteria: either a postoperative AHI decrease $>50 \%$ or a

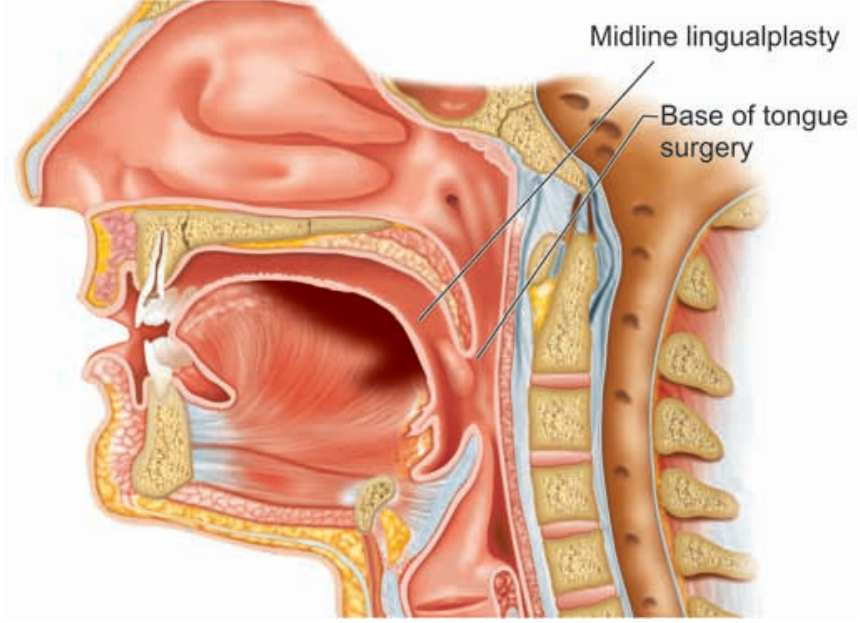

Fig. 3: Technique for lingualplasty (lateral view)

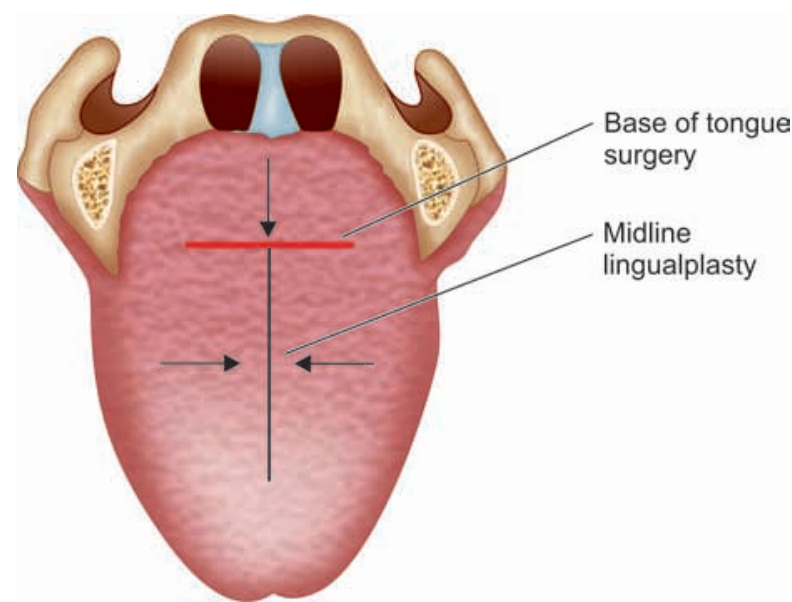

Fig. 4: Sutured line after lingualplasty

residual postoperative $\mathrm{AHI}<20$ events/hour), this was achieved in $58.3 \%$ (35/60 patients) (Table 3 ).

If 'effective' surgical success for OSA is considered (criterion: postoperative $\mathrm{AHI}<$ preoperative $\mathrm{AHI}$ ), this was achieved in $86.7 \%$ (52/60 patients) while the 'ineffective' rate was $13.3 \%$ (8/60 patients) (Table 4 ).

Early postoperative complications comprised velopharyngeal insufficiency (VPI) 20\% (12/60), dysarthria $20 \%(12 / 60$,$) and wound dehiscence 3.33 \%$ (2/60) but VPI

Table 1: Characteristics and parameters of multilevel surgical patients

\begin{tabular}{|c|c|c|c|c|c|c|c|}
\hline Variables & $N$ & Percent & Mean & $S D$ & SE & Min. & Max. \\
\hline Age & 60 & & 48.4 & 49.0 & 8.84 & 26.0 & 69.0 \\
\hline Gender & 60 & 100.0 & & & & & \\
\hline Male & 50 & 83.3 & & & & & \\
\hline Female & 10 & 16.6 & & & & & \\
\hline BMI & 60 & 100.0 & 27.4 & 26.4 & 4.39 & 19.7 & 41.3 \\
\hline Preoperative mean $\mathrm{SpO}_{2}$ & 60 & & 94.3 & 94.8 & 2.54 & 84.2 & 98.0 \\
\hline Postoperative mean $\mathrm{SpO}_{2}$ & 60 & & 95.2 & 95.7 & 2.50 & 84.1 & 98.4 \\
\hline Preoperative lowest $\mathrm{SpO}_{2}$ & 60 & & 79.1 & 11.07 & 1.43 & 52.1 & 96.1 \\
\hline Postoperative lowest $\mathrm{SpO}_{2}$ & 60 & & 84.4 & 7.84 & 1.00 & 53.2 & 97.0 \\
\hline Preoperative $\mathrm{AHI}$ & 60 & & 57.5 & 24.38 & 3.14 & 15.0 & 109.5 \\
\hline Postoperative AHI & 60 & & 29.7 & 25.44 & 3.28 & 0.4 & 95.7 \\
\hline
\end{tabular}

AHI: Apnea-hypopnea index; pre-op: preoperative; post-op: postoperative; $\mathrm{SpO}_{2}$ : peripheral oxygen saturation by pulse oximetry 
Table 2: Differences of mean lowest oxygen saturations $\left(\mathrm{O}_{2}\right.$ Sat, $\left.\mathrm{SpO}_{2}\right)$ and apnea-hypopnea indexes (AHIs) before and after surgery

\begin{tabular}{|c|c|c|c|c|c|c|c|}
\hline & & \multicolumn{6}{|c|}{ Paired samples statistics } \\
\hline & & $N$ & Mean & $S D$ & SE & $t$-test & $p$-value \\
\hline \multirow[t]{2}{*}{ Pair 1} & $\begin{array}{l}\text { Preoperative lowest } \mathrm{O}_{2} \\
\text { sat }\left(\mathrm{SpO}_{2}\right)\end{array}$ & 60 & 79.1 & 11.07 & 1.43 & -4.175 & $<0.001$ \\
\hline & $\begin{array}{l}\text { Postoperative lowest } \mathrm{O}_{2} \\
\text { sat }\left(\mathrm{SpO}_{2}\right)\end{array}$ & 60 & 84.4 & 7.84 & 1.00 & & \\
\hline \multirow[t]{2}{*}{ Pair 2} & Preoperative AHI & 60 & 57.5 & 24.38 & 3.14 & 9.280 & $<0.001$ \\
\hline & Postoperative AHI & 60 & 29.7 & 25.44 & 3.28 & & \\
\hline
\end{tabular}

Table 3: Postoperative changes of apnea-hypopnea indexes

\begin{tabular}{lll}
\hline Postoperative changes in AHI values & $N$ & Percent \\
\hline $\begin{array}{l}\text { AHI decrease }>50 \% \\
\text { or }\end{array}$ & 35 & 58.3 \\
$\mathrm{AHI}<20$ events/hour & & \\
No AHI decrease $>50 \%$ & 25 & 41.7 \\
or & & \\
$\mathrm{AHI} \geq 20$ events/hour & & \\
\hline Total & 60 & 100.0 \\
\hline
\end{tabular}

Table 4: Comparison of preoperative and postoperative apnea-hypopnea indexes (AHIs)

\begin{tabular}{lll}
\hline AHIs & $N$ & Percent \\
\hline Postoperative AHIs < preoperative AHIs (effective) & 52 & 86.7 \\
Postoperative AHIs > preoperative AHIs (ineffective) & 8 & 13.3 \\
\hline Total & 60 & 100.0 \\
\hline
\end{tabular}

cases improved within 90 days. Longer medium-term follow-ups (1-3 years) did not reveal any VPI, abnormal nasality, dysphagia, dysarthria or hypoglossal nerve palsy.

\section{DISCUSSION}

Multilevel surgery, i.e. combined lingualplasty with the new PG and UPPP in moderate to severe OSA patients was successful as assessed by cure rate and effective rate. Such surgery probably expanded pharyngeal air space. It is possible that the new transverse resection of PPG plus anterior-posterior suturing had a role in this expansion.

After this surgery, mean AHI improved significantly (mean AHI decreased significantly- $p<0.001$ ) while mean lowest saturation $\left(\mathrm{SpO}_{2}\right)$ increased significantly (from comparison of preoperative $\mathrm{SpO}_{2}$ and postoperative $\mathrm{SpO}_{2}$ among PSG results, $\mathrm{p}<0.001$ ).

On successful results (criteria: postoperative AHI decrease $>50 \%$ or residual or postoperative AHI $<20$ events/hour), the successful cure rate was achieved in $58.3 \%$ (35/60 patients) (Table 3); and, on effective results (postoperative AHI less than preoperative AHI), the successful effective rate was $86.7 \%$ (52/60 patients) (Table 4 ).

On ineffective results, the 'ineffective' rate was $13.3 \%$ (8/60 patients) (Table 4 ). Both the positive surgical cure rate and the high surgical effective rate emphasize the relevant role of multilevel surgery in the treatment of moderate to severe OSA. It should be mentioned that the multilevel surgery in this study is less extensive than the maxillomandibular advancement surgery; ${ }^{17-20}$ however, more extensive surgery may have a role in treatment of selected patients with OSA. ${ }^{21}$

Although this research has some limitations, such as retrospective design, small number of patients and absence of a control group, there are some positive promising surgical results and future studies are recommended.

\section{CONCLUSION}

In this study, multilevel surgery, i.e. combined lingualplasty (including new PPG) and 'UPPP' represents a minimally invasive technique with aim to improve tongue base collapse and narrowing of oropharynx in patients with multilevel airway obstructions; and, success rates (from AHI results) have emphasized the relevant role of multilevel surgery in moderate to severe OSA patients. Such surgery can be easily performed and should be considered as an alternative choice to CPAP therapy especially in cases with CPAP-intolerance or CPAP-failures. Being relatively inexpensive and less extensive than maxillo-mandibular advancement surgery, this combined lingualplasty and 'UPPP' have sufficiently successful rates to be justified as a treatment for moderate to severe OSA patients.

\section{ACKNOWLEDGMENTS}

The author wishes to thank Dr Worranan Prasanatikom, Prof Amnuay Thithapangha, Faculty of Medicine Ramathibodi Hospital, Mahidol University for help analysis and advice during the preparation of writing the manuscript.

\section{REFERENCES}

1. Young T, Palta M, Dempsey J, Skatrud J, Weber S, Badr S. The occurrence of sleep disordered breathing in middle-aged adults. N Engl J Med 1993;328(17):1230-1235. 
2. Isono S, Remmers JE, Tanaka A, Sho Y, Sato J, Nishino T. Anatomy of the pharynx in patients with obstructive sleep apnea and in normal subjects. J Appl Physiol 1997;82(4): 1319-1326.

3. Gleadhill IC, Schwartz AR, Schubert N, Wise RA, PermuttS, Smith PL. Upper airway collapsibility in snorers and in patients with obstructive sleep apnea. Am Rev Resp Dis 1991;143(6):1300-1303.

4. Nieto JF, Young TB, Lind BK, Shahar E, Nieto FJ, Young TB, et al. Association of sleep-disordered breathing, sleep apnea, and hypertension in a large community-based study: Sleep Heart Health Study. JAMA 2000;283(14):1829-1836.

5. Peppard PE, Young T, Palta M, Skatrund J. Prospective study of the association between sleep-disordered breathing and hypertension. N Engl J Med 2000;342(19):1378-1384.

6. Somers VK, Dyken ME, Clary MP, Abbond FM. Sympathetic neural mechanisms in obstructive sleep apnea. J Clin Invest 1995;96(4):1897-1904.

7. Shahar E, Whitney CW, Redline S, Lee ET, Newman AB, Nieto FJ, et al. Sleep-disordered breathing and cardiovascular disease: cross-sectional results of the Sleep Heart Health Study. Am J Respir Crit Care Med 2001;163(1):19-25.

8. Kribbs NB, Pack AI, Kline LR, Smith PL, Schwartz AR, Schubert NM, et al. Objective measurement of pattern of nasal CPAP use by patients with obstructive sleep apnea. Am Rev Respir Dis 1993;147(4):887-895.

9. Meurice JC, Dore P, Paquereau J, Neau JP, Ingrand P, Chavagnat JJ, et al. Predictive factors of long term compliance with nasal continuous positive airway pressure treatment in sleep apnea syndrome. Chest 1994;105(2):429-433.

10. Tunçel U, Inançli HM, Kürkçüglu SS, Enöz M. Can the Müller maneuver detect multilevel obstruction of the upper airway in patients with obstructive sleep apnea syndrome? Kulak Burun Bogaz Ihtis Derg 2010;20(2):84-88.
11. Fujita S, Conway W, Zorick F, Roth T. Surgical correction of anatomic abnormality in obstructive sleep apnea syndrome: uvulopalatopharyngoplasty. Otolaryngol Head Neck Surg 1981;89(6):923-934.

12. Khan A, Ramar K, Maddirala S, Friedman O, Pallanch JF, Olson EJ. Uvulopalatopharyngoplasty in the management of obstructive sleep apnea: the Mayo Clinic experience. Mayo Clinic Proc 2009;84(9):795-800.

13. Millman RP, Carlisle CC, Rosenberg C, Kahn D, McRae R, Kramer NR. Simple predictors of uvulopalatopharyngoplasty outcome in the treatment of obstructive sleep apnea. Chest 2000;118(4):1025-1030.

14. Harwick JD, 'Preface'. Otolaryngol Clin North Am 2007;40: 11-12.

15. Terris DJ. Multilevel pharyngeal surgery for obstructive sleep apnea syndrome: indication and techniques. Op Tech Otolaryngol Head Neck Surg 2000;11(1):12-20.

16. Sher AE, Schechtman K, Piccarillo JF. The efficacy of surgical modifications of the upper airway in adults with obstructive sleep apnea syndrome. Sleep 1996;19(2):156-177.

17. Riley RW, Powell N, Guilleminault C. Inferior sagittal osteotomy of mandible with hyoid myotomy-suspension: a new procedure for obstructive sleep apnea. Otolaryngol Head Neck Surg 1986;94(5):589-593.

18. Riley RW, Powell N, Guilleminault C. Obstructive sleep apnea syndrome: a review of 306 consecutively treated surgical patients. Otolaryngol Head Neck Surg 1993;108(2):117-125.

19. Riley RW, Powell N, Li KK, Troell RJ, Guilleminault C. Obstructive sleep apnea: long-term clinical outcomes. Otolaryngol Head Neck Surg 2000;122(3):415-421.

20. Li KK. Maxillomandibular advancement for obstructive sleep apnea. Oral Maxillofac Surg 2011;69(3):1659-1677.

21. Lee NR, Givens CD, Wilson J, Robins RB. Staged surgical treatment of obstructive sleep apnea syndrome: a review of 35 patients. J Oral Maxillofac Surg 1999;57(4):382-385. 